\title{
Low Serum Pancreatic Amylase and Lipase Values Are Simple and Useful Predictors to Diagnose Chronic Pancreatitis
}

Hyoung-Chul Oh ${ }^{1,2}$, Chang-II Kwon ${ }^{1}$, Ihab I. El Hajj ${ }^{1}$, Jeffrey J. Easler ${ }^{1}$, James Watkins ${ }^{1}$, Evan L. Fogel ${ }^{1}$, Lee McHenry ${ }^{1}$, Stuart Sherman ${ }^{1}$, Michelle K. Zimmerman ${ }^{3}$, and Glen A. Lehman ${ }^{1}$

${ }^{1}$ Division of Gastroenterology and Hepatology, Indiana University School of Medicine, Indianapolis, IN, USA, ${ }^{2}$ Division of Gastroenterology, Chung-Ang University College of Medicine, Seoul, Korea, and ${ }^{3}$ Department of Pathology and Laboratory Medicine, Indiana University School of Medicine, Indianapolis, IN, USA

Background/Aims: This study aimed to evaluate the diagnostic role of low serum amylase and lipase values in the detection of chronic pancreatitis. Methods: Patients underwent endoscopic retrograde cholangiopancreatography and were diagnosed with non-calcific chronic pancreatitis (NCCP; $n=99$ ) and calcific chronic pancreatitis (CCP; $n=112$ ). Patient serum amylase and lipase values were compared with those of healthy controls $(H ; n=170)$. Results: The median serum amylase (normal range, 19 to $86 \mathrm{U} / \mathrm{L}$ ) and lipase values (7 to $59 \mathrm{U} / \mathrm{L})\left(\mathrm{P}_{25}-\mathrm{P}_{75}\right)$ were 47.0 (39.8 to 55.3) and 25.0 (18.0 to 35.0 ) for $\mathrm{H}, 34.0$ (24.5 to 49.0 ) and 19.0 (9.0 to 30.0) for NCCP, and 30.0 (20.0 to 40.8) and 10.0 (3.0 to 19.0) for $\mathrm{CCP}$, respectively. The cutoff values with the highest diagnostic accuracy for discriminating NCCP from $\mathrm{H}$ were $40 \mathrm{U} / \mathrm{L}$ for amylase and $20 \mathrm{U} / \mathrm{L}$ for lipase, respectively, and for CCP from $\mathrm{H}$ were $38 \mathrm{U} / \mathrm{L}$ for amylase and $15 \mathrm{U} / \mathrm{L}$ for lipase, respectively. For the diagnosis of NCCP with a criterion of serum amylase $<40$ and lipase $<20 \mathrm{U} / \mathrm{L}$, the sensitivity, specificity, positive predictive value, and negative predictive values were $37.4 \%, 88.8 \%, 66.1 \%$, and $70.9 \%$, respectively. Conclusions: Serum amylase and/or lipase levels below the normal serum range are highly specific for chronic pancreatitis patients. Clinicians should not ignore low serum pancreatic enzyme values. (Gut Liver 2017;11:878-883)

Key Words: Amylases; Lipase; Pancreatitis, chronic

\section{INTRODUCTION}

Achieving a diagnosis of disease with a simple method is helpful in clinical practice. Chronic pancreatitis encompasses a wide range of progressive fibro-inflammatory diseases of the exocrine pancreas that eventually lead to damage of the gland. With progression, failure of exocrine and endocrine pancreatic function eventually may occur. ${ }^{1}$ Chronic pancreatitis may initially present with clinically apparent acute pancreatitis. Repeated episodes of acute pancreatitis progress to development of established chronic pancreatitis, with intraductal stones, pancreatic ductal distortion, strictures and pancreatic atrophy. ${ }^{2,3}$ Clinically, eventual extensive destruction of the pancreatic parenchyma may result in malabsorption and steatorrhea, and diabetes mellitus.

The pancreas synthesizes and secretes more than 10 enzymes, including amylase and lipase, that hydrolyze macronutrients including carbohydrate, fat and protein within the lumen of the small bowel. Serum amylase and lipase values have been widely used for the diagnosis of acute inflammatory states of the pancreas. As the secretory capacity of the pancreas decreases during the course of chronic pancreatitis, serum amylase and lipase values may decrease according to the residual functional capacity. $^{3}$

In clinical practice, when serum pancreatic enzyme values are elevated, further pancreatic evaluation is often warranted. In contrast, when the value is normal or low, no specific next step is suggested. Previous studies published a few decades ago suggested the diagnostic role of low pancreatic serum enzyme values in chronic pancreatitis. ${ }^{4-7}$ In a recent study, low serum pancreatic lipase value was a useful indicator for the discrimination of established calcific chronic pancreatitis (CCP) versus healthy controls $(\mathrm{H}){ }^{8}$ The low lipase finding is of less diagnostic value since the diagnosis is obvious via calcification. To date, few studies addressed the diagnostic role of serum amylase and

Correspondence to: Glen A. Lehman

Division of Gastroenterology and Hepatology, Indiana University School of Medicine, 550 N. University Boulevard, Suite 1634, Indianapolis, IN 46202, USA

Tel: +1-317-948-3684, Fax: +1-317-948-3846, E-mail: glehman@iu.edu Received on February 9, 2017. Revised on April 12, 2017. Accepted on May 16, 2017. pISSN 1976-2283 eISSN 2005-1212 https://doi.org/10.5009/gnl17066

(a) This is an Open Access article distributed under the terms of the Creative Commons Attribution Non-Commercial License (http://creativecommons.org/licenses/by-nc/4.0) which permits unrestricted non-commercial use, distribution, and reproduction in any medium, provided the original work is properly cited. 
lipase in the discrimination of chronic pancreatitis at the noncalcific stage of disease from $\mathrm{H}$. This study aimed to evaluate the diagnostic role of low serum pancreatic amylase and lipase values in the detection of non-calcific chronic pancreatitis (NCCP).

\section{MATERIALS AND METHODS}

Healthy paid volunteers were screened and prospectively enrolled in the control group. ${ }^{8}$ Consecutive patients who were diagnosed with chronic pancreatitis at Indiana University Hospital were selected from the Indiana University endoscopic retrograde cholangiopancreatography (ERCP) database during the period between December 2012 and November 2015 and enrolled in the patient groups. Patients with chronic pancreatitis were divided into NCCP and CCP group based on the presence or absence of calcification seen on computed tomography (CT) scan, plain abdominal X-ray or ERCP. Serum amylase and lipase values were compared among the three groups. This study was approved by Indiana University Institutional Review Board (No. 1310570729A006).

\section{Control group}

Healthy volunteers were screened and prospectively enrolled in the control group from April 1, 2014 to March 15, 2015. Informed consent was obtained from all volunteers before enrollment. Inclusion criteria and exclusion criteria were described in our previous study. Aliquots of blood samples from a single draw were analyzed for serum pancreatic enzyme levels.

\section{Patient group}

Patients who were diagnosed with chronic pancreatitis based on ERCP (endoscopic ultrasound [EUS] in selected cases) at In- diana University between December 2012 and November 2015 were enrolled in the patient group. All information was obtained by retrospective medical record review from patients who were identified through the Indiana University ERCP database. NCCP was diagnosed based on at least one of three imaging studies (CT, $n=40$; magnetic resonance imaging [MRI], $n=56$; EUS, $n=47$ ) with parenchymal and ductal changes except calcification, and confirmed with endoscopic retrograde pancreatography abnormalities. NCCP was classified into two categories (mild/moderate and severe) based on the severity of pancreatography findings according to the published criteria. ${ }^{4}$ CCP was diagnosed based on clinical symptoms and pancreatic calcifications as well as parenchymal and ductal changes detected by imaging studies (CT, n=69; MRI, n=17; EUS, n=18; fluoroscopy, $n=8$ ) and confirmed with ERP abnormalities. Blood samples for serum amylase and lipase values were obtained and analyzed a few hours before the ERCP by the routine clinical laboratory of the Indiana University Health. Patients were excluded from the study if they were younger than 18 years or older than 79 years or pregnant or had a condition such as chronic kidney disease, previous gastrointestinal or pancreatic surgery that may affect serum amylase and lipase levels.

\section{Analysis of serum pancreatic enzymes}

All serum amylase and lipase values in the three groups were measured using same automated chemistry analyzer (AU 5822 analyzer; Beckman Coulter, Brea, CA, USA). Our validated reference range for amylase and lipase are between $19 \mathrm{U} / \mathrm{L}$ and 86 U/L, and between $7 \mathrm{U} / \mathrm{L}$ and $59 \mathrm{U} / \mathrm{L}$, respectively.

Serum amylase and lipase values were compared among the three groups. Patients with above the upper normal range of serum enzyme value (amylase $>86 \mathrm{U} / \mathrm{L}$ and lipase $>59 \mathrm{U} / \mathrm{L}$ ) before ERCP were excluded in the study.

Table 1. Baseline Characteristics of Enrolled Subjects

\begin{tabular}{|c|c|c|c|c|}
\hline Characteristic & Healthy (n=170) & NCCP (n=99) & $\mathrm{CCP}(\mathrm{n}=112)$ & $\mathrm{p}$-value \\
\hline Age, yr & $49.0(32.8-62.0)$ & $50.6(39.2-62.2)$ & $53.7(46.0-63.8)^{*}$ & 0.020 \\
\hline Male sex & 44 (25.9) & $38(38.4)$ & $51(45.6)^{*}$ & 0.002 \\
\hline Amylase, $\mathrm{U} / \mathrm{L}^{\dagger}$ & $47.0(39.8-55.3)$ & $34.0(24.5-49.0)^{\ddagger}$ & $31.7(20.0-40.8)^{\ddagger, \S}$ & $<0.001$ \\
\hline Lipase, U/L" & $25.0(18.0-35.0)$ & $22.3(9.0-30.0)^{\dagger}$ & $10.0(3.0-19.0)^{ \pm, \uparrow}$ & $<0.001$ \\
\hline \multicolumn{5}{|l|}{ Cause of pancreatitis } \\
\hline Alcohol & - & 19 & 63 & \\
\hline Idiopathic & - & 57 & 24 & \\
\hline Smoking & - & 6 & 2 & \\
\hline Autoimmune & - & 5 & 0 & \\
\hline Pancreas divisum & - & 5 & 8 & \\
\hline Others & - & 3 & 9 & \\
\hline
\end{tabular}

Data are presented as median $\left(\mathrm{P}_{25}-\mathrm{P}_{75}\right)$ or number (\%).

NCCP, non-calcific chronic pancreatitis; CCP, calcific chronic pancreatitis; $\mathrm{P}_{25}-\mathrm{P}_{75}, 25$ th and 75 th percentiles.

${ }^{*} \mathrm{p}<0.05 ;{ }^{\dagger}$ Normal value, $19-86 \mathrm{U} / \mathrm{L} ;{ }^{\ddagger} \mathrm{p}<0.001$ compared to healthy individuals; ${ }^{\$} \mathrm{p}<0.05$; "Normal value, 7-59 U/L; ${ }^{\mathrm{p}} \mathrm{p}<0.001 \mathrm{between} \mathrm{NCCP}$ and CCP. 


\section{Statistical analysis}

Values are expressed as median with 25th and 75th percentiles $\left(\mathrm{P}_{25}-\mathrm{P}_{75}\right)$ or absolute number. For comparison of continuous values, the values were first evaluated for normality of distribution using the Shapiro-Wilk test. As age, serum amylase and lipase values did not pass the normality test, they were analyzed using Kruskal-Wallis test followed by Mann-Whiney U test with Bonferroni correction.

Separate receiver operator characteristic (ROC) curves were plotted using serum amylase and lipase values to predict chronic pancreatitis. The area under each ROC curve, a measure of predictive power, was calculated. For both serum amylase and lipase, a cutoff value was selected to maximize the proportion of correct discrimination of chronic pancreatitis. Sensitivity and specificity were determined using these values. Sensitivity, specificity, positive predictive value (PPV), and negative predictive value (NPV) were compared using two-sample tests of proportions. Using same method, cutoff at $0,10,20$, and 30 percentile of normal range of serum amylase and cutoff at $0,5,10$, and 15 percentile of normal range of serum lipase were selected to compare sensitivity, specificity, PPV, and NPV. A p-value $<0.05$ was considered significant. All analyses were performed using SPSS version 18.0 (SPSS Inc., Chicago, IL, USA).

\section{RESULTS}

\section{Serum amylase and lipase values}

Baseline characteristics and mean serum amylase and lipase values are summarized in Table 1. Median age $\left(\mathrm{P}_{25}-\mathrm{P}_{75}\right)$ was 49.0 years (32.8 to 62.0 years) for $\mathrm{H}, 50.6$ years (39.2 to 62.2 years) for NCCP, and 53.7 years (46.0 to 63.8 years) for CCP, respec- tively. The proportion of male subjects was 25.9\% for $\mathrm{H}, 38.4 \%$ for NCCP, and 45.6\% for CCP, respectively. Median serum amylase value (normal range, 19 to $86 \mathrm{U} / \mathrm{L} ; \mathrm{P}_{25}-\mathrm{P}_{75}$ ) was $47.0 \mathrm{U} / \mathrm{L}$ (39.8 to $55.3 \mathrm{U} / \mathrm{L}$ ) for $\mathrm{H}, 34.0 \mathrm{U} / \mathrm{L}(24.5$ to $49.0 \mathrm{U} / \mathrm{L}$ ) for NCCP, $31.7 \mathrm{U} / \mathrm{L}(20.0$ to $40.8 \mathrm{U} / \mathrm{L})$ for CCP $(\mathrm{p}<0.001)$. Median serum lipase value (normal range, 7 to $59 \mathrm{U} / \mathrm{L} ; \mathrm{P}_{25}-\mathrm{P}_{75}$ ) was $25.0 \mathrm{U} / \mathrm{L}(18.0$ to $35.0 \mathrm{U} / \mathrm{L}$ ) for $\mathrm{H}, 22.3 \mathrm{U} / \mathrm{L}$ (9.0 to $30.0 \mathrm{U} / \mathrm{L}$ ) for NCCP, $10.0 \mathrm{U} /$ L (3.0 to $19.0 \mathrm{U} / \mathrm{L}$ ) for CCP $(\mathrm{p}<0.001)$. Fig. 1 shows the distribution of serum amylase (A) and lipase (B) values among the five groups.

Median serum amylase values $\left(\mathrm{P}_{25}-\mathrm{P}_{75}\right)$ were compared according to the severity of chronic pancreatitis; $34.0 \mathrm{U} / \mathrm{L}$ (27.0 to $48.0 \mathrm{U} / \mathrm{L}$ ) for moderate NCCP ( $\mathrm{n}=66), 34.5 \mathrm{U} / \mathrm{L}$ (22.3 to $56.5 \mathrm{U} /$ L) for severe NCCP ( $\mathrm{n}=33)$, and $30.0 \mathrm{U} / \mathrm{L}(20.0$ to $40.8 \mathrm{U} / \mathrm{L})$ for CCP. There was significant difference between moderate NCCP and CCP $(\mathrm{p}<0.05)$, but no difference between severe NCCP and CCP $(p=0.119)$. For serum lipase values, median values $\left(\mathrm{P}_{25}-\right.$ $\mathrm{P}_{75}$ ) were $20.0 \mathrm{U} / \mathrm{L}$ (12.8 to $\left.30.5 \mathrm{U} / \mathrm{L}\right)$ for moderate NCCP $(\mathrm{n}=66)$, $15.0 \mathrm{U} / \mathrm{L}$ (4.0 to $32.0 \mathrm{U} / \mathrm{L}$ ) for severe NCCP ( $\mathrm{n}=33)$, and $10.0 \mathrm{U} /$ $\mathrm{L}$ (3.0 to $19.0 \mathrm{U} / \mathrm{L}$ ) for CCP. There was also significant difference between moderate NCCP and CCP $(\mathrm{p}<0.001)$, but no significant difference between severe NCCP and CCP ( $\mathrm{p}=0.056)$.

\section{Cutoff values of serum amylase and lipase between $\mathbf{H}$ and NCCP}

Sensitivity and specificity curves demonstrated that the optimal cutoff value for serum amylase and lipase corresponded to the intersection of the sensitivity and specificity curves (Fig. 2). Serum amylase with a cutoff value of $40 \mathrm{U} / \mathrm{L}$ provided the greatest diagnostic accuracy with sensitivity of 56.6\% and specificity of 75.3\% for differentiating between H and NCCP. Serum lipase value with a cutoff value of $20 \mathrm{U} / \mathrm{L}$ provided the

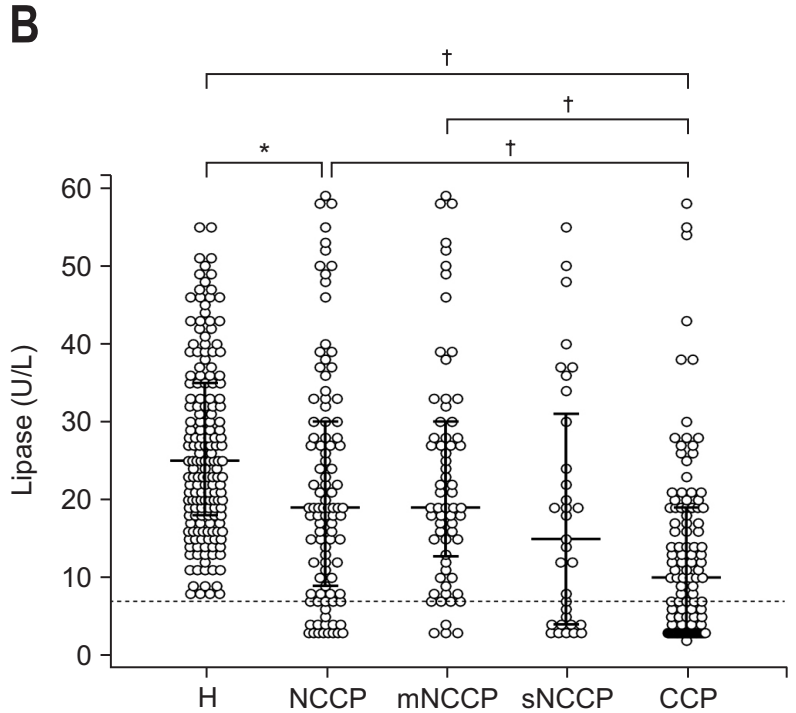

Fig. 1. Serum amylase (A) and lipase (B) values among the five groups. $\mathrm{H}$, healthy control group; NCCP, non-calcific chronic pancreatitis; mNCCP, moderate NCCP; sNCCP, severe NCCP; CCP, calcific chronic pancreatitis. ${ }^{*} \mathrm{p}<0.05 ;{ }^{\dagger} \mathrm{p}<0.001$. 

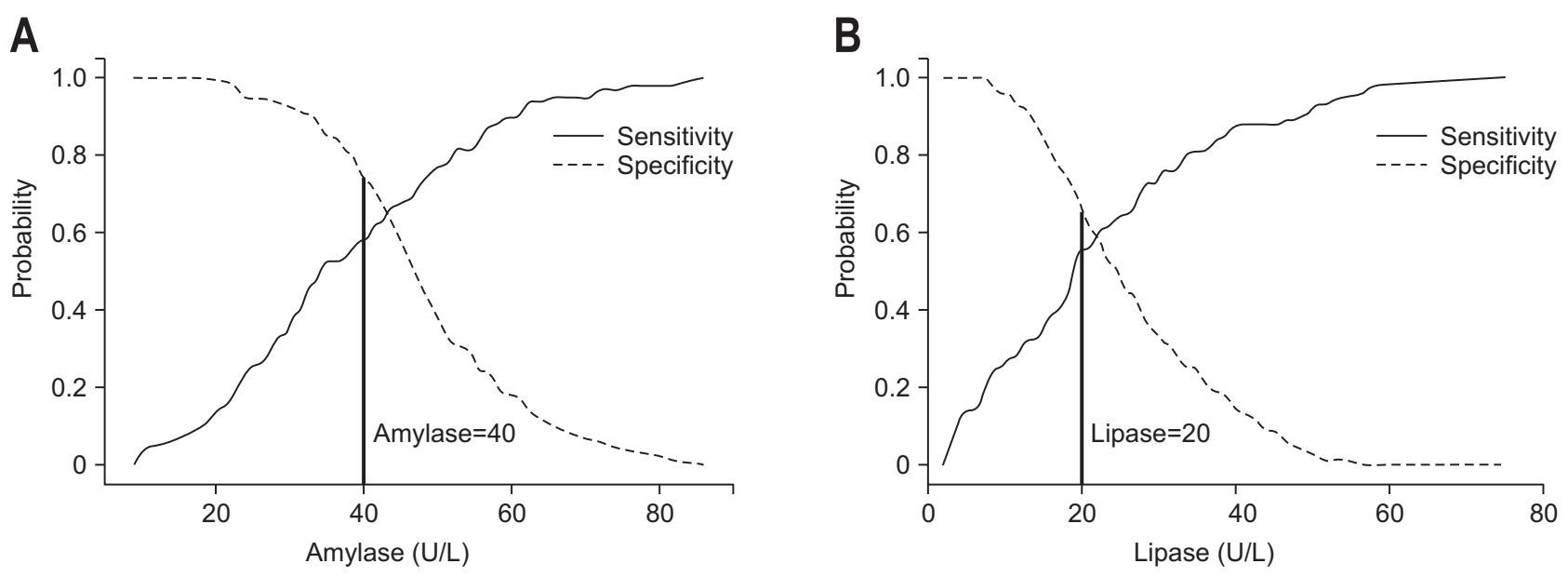

Fig. 2. (A) Sensitivity and specificity curves of serum amylase values to differentiate between healthy subjects and non-calcific chronic pancreatitis. Optimal cutoff values of $40 \mathrm{U} / \mathrm{mL}$ for amylase correlated with the crossover of the sensitivity and specificity curves. (B) Sensitivity and specificity curves of serum lipase values to differentiate between healthy subjects and non-calcific chronic pancreatitis. Optimal cutoff values of $20 \mathrm{U} / \mathrm{L}$ for lipase correlated with the crossover of the sensitivity and specificity curves.

Table 2. Diagnostic Accuracy of Serum Amylase and Lipase to Differentiate Non-Calcific Chronic Pancreatitis from Healthy Subjects

\begin{tabular}{|c|c|c|c|c|c|}
\hline & Percentile & Sensitivity, \% & Specificity, \% & PPV, \% & NPV, \% \\
\hline \multicolumn{6}{|l|}{ Amylase, U/L* } \\
\hline 19.0 & 0 & 10.6 & 100.0 & 100.0 & 65.6 \\
\hline 25.7 & 10 & 25.3 & 94.7 & 73.5 & 68.5 \\
\hline 32.4 & 20 & 44.4 & 90.6 & 73.3 & 73.3 \\
\hline 39.1 & 30 & 56.6 & 75.3 & 57.1 & 74.9 \\
\hline 40.0 & Optimal cutoff & 56.6 & 75.3 & 57.1 & 74.9 \\
\hline \multicolumn{6}{|l|}{ Lipase, $\mathrm{U} / \mathrm{L}^{\dagger}$} \\
\hline 7.0 & 0 & 15.2 & 100.0 & 100.0 & 66.9 \\
\hline 9.6 & 5 & 25.3 & 95.9 & 78.1 & 68.8 \\
\hline 12.2 & 10 & 31.3 & 92.4 & 70.5 & 68.8 \\
\hline 14.8 & 15 & 33.3 & 86.5 & 58.9 & 69.0 \\
\hline 17.4 & 20 & 41.4 & 75.9 & 50.5 & 69.0 \\
\hline 20.0 & Optimal cutoff & 54.5 & 68.8 & 50.0 & 72.2 \\
\hline Amylase $<40$ and lipase $<20 \mathrm{U} / \mathrm{L}$ & & 37.4 & 88.8 & 66.1 & 70.9 \\
\hline Amylase $<40$ or lipase $<20 \mathrm{U} / \mathrm{L}$ & & 73.7 & 55.3 & 49.0 & 78.3 \\
\hline
\end{tabular}

PPV, positive predictive value; NPV, negative predictive value.

*Normal, 19-86 U/L; ${ }^{\dagger}$ Normal, 7-59 U/L.

greatest accuracy with sensitivity of 54.5\% and specificity of $68.8 \%$. With combined use of optimal cutoff values of $<40 \mathrm{U} /$ $\mathrm{L}$ for serum amylase and $<20 \mathrm{U} / \mathrm{L}$ for serum lipase, diagnostic accuracy with sensitivity of $37.4 \%$ and specificity of $88.8 \%$ was observed (Table 2). Diagnostic parameters at four different cutoff values that correspond to four different percentiles are also summarized at Table 2 .

\section{Cutoff values of serum amylase and lipase between $H$ and CCP}

Sensitivity and specificity curves demonstrated that the op- timal cutoff value for serum amylase and lipase corresponded to the intersection of the sensitivity and specificity curves (Fig. 3). Serum amylase with a cutoff value of $38 \mathrm{U} / \mathrm{L}$ provided the greatest diagnostic accuracy with sensitivity of 70.5\% and specificity of $81.2 \%$ for differentiating between $\mathrm{H}$ and CCP. Serum lipase value with a cutoff value of $15 \mathrm{U} / \mathrm{L}$ provided the greatest accuracy with sensitivity of $67.0 \%$ and specificity of $86.5 \%$. With combined use of optimal cutoff values of $<38$ U/L for serum amylase and $<15 \mathrm{U} / \mathrm{L}$ for serum lipase, diagnostic accuracy with sensitivity of 55.4\% and specificity of 93.5\% was observed (Table 3). Diagnostic parameters at four different cutoff values 
A

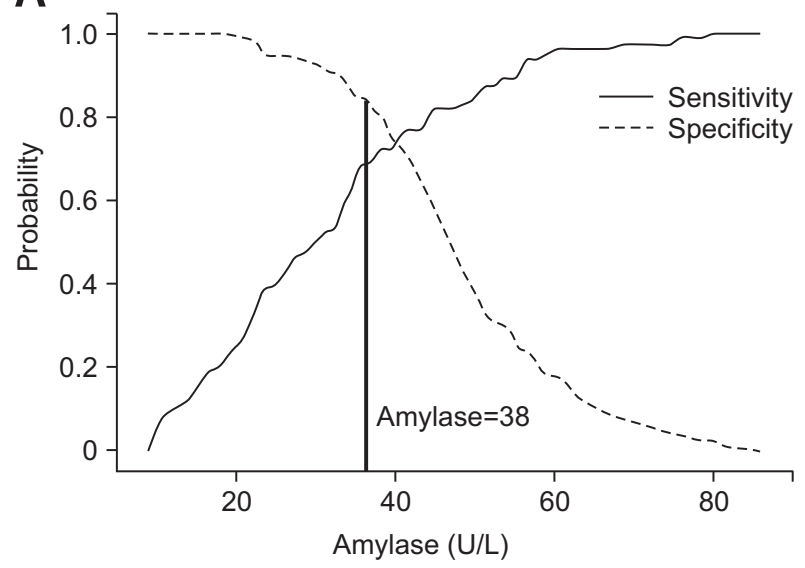

B

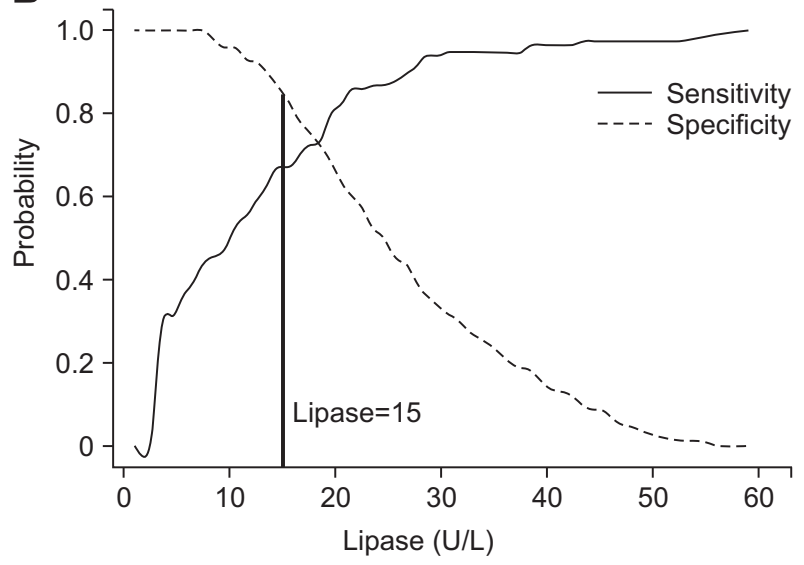

Fig. 3. (A) Sensitivity and specificity curves of serum amylase values to differentiate between healthy subjects and calcific chronic pancreatitis. Optimal cutoff values of $38 \mathrm{U} / \mathrm{mL}$ for amylase correlated with the crossover of the sensitivity and specificity curves. (B) Sensitivity and specificity curves of serum lipase values to differentiate between healthy subjects and calcific chronic pancreatitis. Optimal cutoff values of $15 \mathrm{U} / \mathrm{L}$ for lipase correlated with the crossover of the sensitivity and specificity curves.

Table 3. Diagnostic Accuracy of Serum Amylase and Lipase for Differentiating Calcific Chronic Pancreatitis from Healthy Subjects

\begin{tabular}{|c|c|c|c|c|c|}
\hline & Percentile & Sensitivity, \% & Specificity, \% & PPV, \% & NPV, \% \\
\hline \multicolumn{6}{|l|}{ Amylase, $\mathrm{U} / \mathrm{L}^{*}$} \\
\hline 19.0 & 0 & 21.4 & 100.0 & 100.0 & 65.9 \\
\hline 25.7 & 10 & 41.1 & 94.7 & 83.6 & 70.9 \\
\hline 32.4 & 20 & 53.6 & 90.6 & 78.9 & 74.8 \\
\hline 38.0 & Optimal cutoff & 70.5 & 81.2 & 71.2 & 80.5 \\
\hline 39.1 & 30 & 72.3 & 75.3 & 65.9 & 80.7 \\
\hline \multicolumn{6}{|l|}{ Lipase, $\mathrm{U} / \mathrm{L}^{\dagger}$} \\
\hline 7.0 & 0 & 39.3 & 100.0 & 100.0 & 71.4 \\
\hline 9.6 & 5 & 47.3 & 95.9 & 88.3 & 73.4 \\
\hline 12.2 & 10 & 58.9 & 92.4 & 83.5 & 77.3 \\
\hline 14.8 & 15 & 67.0 & 86.5 & 76.5 & 79.9 \\
\hline 15.0 & Optimal cutoff & 67.0 & 86.5 & 76.5 & 79.9 \\
\hline Amylase $<38$ and lipase $<15$ U/L & & 55.4 & 93.5 & 84.9 & 76.1 \\
\hline Amylase $<38$ or lipase $<15 \mathrm{U} / \mathrm{L}$ & & 82.1 & 74.1 & 67.6 & 86.3 \\
\hline
\end{tabular}

PPV, positive predictive value; NPV, negative predictive value.

*Normal, 19-86 U/L; ${ }^{\dagger}$ Normal, 7-59 U/L.

that correspond to four different percentiles are also summarized at Table 3.

\section{DISCUSSION}

This study demonstrates that the low serum amylase and lipase values have been rediscovered as an important and useful predictor for the detection of NCCP as well as CCP.

For the viewpoint of statistical analysis, optimal cutoff values for serum amylase and lipase were set at $40 \mathrm{U} / \mathrm{L}$ and $20 \mathrm{U} / \mathrm{L}$ for the comparison between $\mathrm{H}$ and NCCP with modest sensitivity and specificity, and $38 \mathrm{U} / \mathrm{L}$ and $15 \mathrm{U} / \mathrm{L}$ for the comparison between $\mathrm{H}$ and $\mathrm{CCP}$ with an increased diagnostic accuracy.
However, in clinical practice, it is better to predict whether the patient has a lower possibility of chronic pancreatitis with these serum amylase and lipase test as the incidence rate of chronic pancreatitis, about 4 per 100,000 people (or person-years), is relatively low. ${ }^{9,10}$ Therefore, the cutoff values at a higher specificity ( $\geq 90 \%$ ), $32 \mathrm{U} / \mathrm{L}$ for amylase and $12 \mathrm{U} / \mathrm{L}$ for lipase, have greater predictive value for the absence of chronic pancreatitis.

The current study confirmed that serum pancreatic enzymes decline with worsening chronic pancreatitis. The median serum amylase and lipase values showed a tendency to decrease when the values from moderate and severe NCCP were compared with those of CCP. Serum lipase value tended to decrease more obviously according to the progression of chronic pancreatitis. In 
addition, serum lipase value showed a higher diagnostic accuracy in detection of CCP from $\mathrm{H}$ compared with serum amylase value.

Very low values of serum trypsin were observed in patients with advanced chronic pancreatitis, with low sensitivities of $33 \%$ to $65 \% .^{11-13}$ A very low level of serum trypsin $(<20 \mathrm{ng} /$ $\mathrm{mL}$; mean serum values [ \pm 2 standard deviation] for $\mathrm{H}$ were 45.9 $[ \pm 26.9])$ is reasonably specific for advanced chronic pancreatitis with steatorrhea. ${ }^{12}$ The serum trypsin assay has not replaced amylase and lipase test in clinical practice due to requiring several days to obtain a result, and 2- to 4-fold more expensive than serum amylase and lipase tests.

There are some limitations in this study. This study was conducted as retrospective review of patients with chronic pancreatitis. Prospective evaluation of NCCP with EUS may better allow defining the relationship between serum amylase and lipase level and natural course of NCCP. Although consecutive patients with chronic pancreatitis were analyzed to minimize the selection bias, only one-fifth of NCCP patients presumably had early stage of chronic pancreatitis; 21 of 99 NCCP patients showed normal CT and/or MR finding and 20 of 99 patients were diagnosed based on EUS. Even if these patients are NCCP, patients with advanced form of NCCP were probably selected in this study and it may increase the possibility of selection bias. A prospective study that involves patients who show normal CT and/or MR finding, and are diagnosed as NCCP only with EUS will discover further. Lastly, the optimal cutoff values for serum amylase (40 U/L) and lipase (20 U/L) for the comparison between $\mathrm{H}$ and NCCP have a relatively low sensitivity. Therefore, it is better to use strict cutoff values at a higher specificity $(>90 \%)$ to exclude the possibility of chronic pancreatitis and to consider further study in the highly selected patients to evaluate the presence of chronic pancreatitis. The real clinical value of these amylase and lipase values is aforementioned (in the second paragraph of Discussion) noting that very low values have low sensitivity but very high specificity for chronic pancreatitis. Therefore, the occasional patient with very low lipase (in the absence of surgical resection) has high probability of chronic pancreatitis.

In conclusion, serum amylase and/or lipase below the serum normal range have high specificity for chronic pancreatitis. Low normal range serum amylase and/or lipase suggests chronic pancreatitis but with lower specificity. When combined amylase and lipase values are low, these should not be discarded, and further testing may well be warranted if there is the possibility of underlying pancreatic disease.

\section{CONFLICTS OF INTEREST}

No potential conflict of interest relevant to this article was reported.

\section{ACKNOWLEDGEMENTS}

Author contributions: H.C.O., data collection, analysis, and drafting; C.I.K., data collection and analysis; J.J.E., I.I.E.H, J.W., E.L.F., and L.M., data collection; S.S., data collection and supervision; M.K.Z., laboratory analysis; G.A.L., study design, supervision and drafting.

\section{REFERENCES}

1. Majumder S, Chari ST. Chronic pancreatitis. Lancet 2016;387: 1957-1966.

2. Ammann RW, Muellhaupt B. The natural history of pain in alcoholic chronic pancreatitis. Gastroenterology 1999;116:1132-1140.

3. Layer P, Holtmann G. Pancreatic enzymes in chronic pancreatitis. Int J Pancreatol 1994;15:1-11.

4. Ammann RW, Akovbiantz A, Largiader F, Schueler G. Course and outcome of chronic pancreatitis: longitudinal study of a mixed medical-surgical series of 245 patients. Gastroenterology 1984;86(5 Pt 1):820-828.

5. Benini L, Caliari S, Vaona B, et al. Variations in time of serum pancreatic enzyme levels in chronic pancreatitis and clinical course of the disease. Int J Pancreatol 1991;8:279-287.

6. Ventrucci M, Gullo L, Daniele C, et al. Comparative study of serum pancreatic isoamylase, lipase, and trypsin-like immunoreactivity in pancreatic disease. Digestion 1983;28:114-121.

7. Ventrucci M, Pezzilli R, Gullo L, Platé L, Sprovieri G, Barbara L. Role of serum pancreatic enzyme assays in diagnosis of pancreatic disease. Dig Dis Sci 1989;34:39-45.

8. Kwon CI, Kim HJ, Korc P, et al. Can we detect chronic pancreatitis with low serum pancreatic enzyme levels? Pancreas 2016;45:1184-1188.

9. Johnson CD, Hosking S. National statistics for diet, alcohol consumption, and chronic pancreatitis in England and Wales, 196088. Gut 1991;32:1401-1405.

10. Yadav D, Timmons L, Benson JT, Dierkhising RA, Chari ST. Incidence, prevalence, and survival of chronic pancreatitis: a population-based study. Am J Gastroenterol 2011;106:2192-2199.

11. Andriulli A, Masoero G, Felder M, et al. Circulating trypsin-like immunoreactivity in chronic pancreatitis. Dig Dis Sci 1981;26:532537.

12. Jacobson DG, Curington C, Connery K, Toskes PP. Trypsin-like immunoreactivity as a test for pancreatic insufficiency. N Engl J Med 1984;310:1307-1309.

13. Borgström A, Wehlin L. Correlation between serum concentrations of three specific exocrine pancreatic proteins and pancreatic duct morphology at ERCP examinations. Scand J Gastroenterol 1984;19:220-227. 